\title{
WHAT THE BRICKS TELL US FROM A TEMPLE AT BURKHAN KHALDUN MOUNTAINS: CHRONOLOGICAL INSIGHTS FROM PIRIR LUMINESCENCE
}

\author{
Saran $S .{ }^{I^{*}}$, Tengis $S .{ }^{1}$ and Tsogtbaatar B. ${ }^{2}$ \\ 1. Institute of Physics and Technology, Mongolian Academy of Sciences, Mongolia \\ 2. Institute of History and Archaeology, Mongolian Academy of Sciences, Mongolia \\ *corresponding author: e-mail: saran.solongo@gmail.com
}

\begin{abstract}
The Burkhan Khaldun Mountains (Mongolia) and its surrounding sacred landscape are associated with Genghis Khan's birth and burial place as described in "The Secret History of the Mongols". It was listed as a UNESCO World Heritage Site on 4 July 2015 under the title "Great Burkhan Khaldun Mountain and its surrounding sacred landscape."

This study offered a great opportunity to apply the recently developed post-IR infrared luminescence (pIRIR) approach to feldspar using coarse and polymineral fine grain techniques and determine the manufacturing date of a brick sample associated with the ruins of the Buddhist temple at the Burkhan Khaldun Mountains. Furthermore, the mineralogical composition of different blue-grey colored bricks from various temple buildings such as the Buddhist temples in Karakorum, Dugan in Erdene Zuu and Avargyn Balgas were studied. The original place and date of manufacturing of the bricks was revealed using the pIRIR ${ }_{180}$ and pIRIR $_{240}$ from coarse and fine grains from a heated feldspar sample and were $1280 \pm 40 \mathrm{AD}$ and $1230 \pm 50 \mathrm{AD}$, correspondingly, which falls into the time period of extensive constructions in Karakorum.
\end{abstract}

Keyboards: luminescence dating, pIRIR, RHX, compositional analysis, brick;

\section{INTRODUCTION}

Historical building dating using luminescence methods measures the last heating of the mineral grains in fired ceramics, including bricks and tiles. Brick dating, however, in comparison to pottery or geological sediment dating is rather rarely reported in literature; Bailiff [1] used optically stimulated luminescence (OSL) [2] on quartz inclusions extracted from brick, obtaining advantages in terms of signal sensitivity compared with thermoluminescence (TL) ones [3]. The problem of re-using of Roman bricks in the construction of the churches is frequently reported [4]. However, luminescence technique is unique when no organic material for radiocarbon dating is available. In Mongolia, luminescence dating was introduced and successfully applied by Saran [5] to the brick fragments, tiles and terracotta figures in order to get information about the construction phases at the ancient resident city Karakorum (Mongolia). Fourteen 
down-draught kilns for burning clay bricks were excavated by the Mongolian-German Karakorum Expedition (MDKE); nine of the recovered kilns were almost completely intact [6]. According to this evidence the Orkhon kiln site and manufactures of the $13^{\text {th }} / 14^{\text {th }}$ century was a demonstrable part of the "imperial manufacturing city" of Karakorum.

Extensive luminescence studies on bricks samples from Karakorum, Mongolia revealed the effect of the strong medium component on the dose evaluation [7] in heated quartz extracted from blue-grey colored bricks. In contrast, the red-colored brick showed a high OSL intensity with dominant fast component. In particular, a comparative study of quartz and feldspar doses was carried out [8] in order to get an accurate dose estimate on the chronology of the brick production [7], as well as the construction phases of the Buddhist temple complex at the Karakorum [8].

However, the application of infrared stimulated luminescence (IRSL) dating of $\mathrm{K}$-feldspars has long been limited due to anomalous fading [9]. Recently developed single-aliquot post-IR IRSL protocol employs infrared stimulation of K-feldspar at elevated temperatures following the IR stimulation at $50^{\circ} \mathrm{C}$, which empties charge carriers in unstable traps before measuring the signal from the more stable traps without any contribution of those unstable traps.

The purpose of this work was to retain all information about the bricks associated with the ruins of the Buddhist temple "Dund Ovoo" at the Burkhan Khaldun Mountain. The study offered a great opportunity to apply the pIRIR [10] approach to fired feldspar using coarse grain and polymineral fine grain techniques. In addition, a mass-gain dating method based on the slow rehydroxylation process of clay fired in the past - the RHX dating method [11] for ceramics will be tested. Compositional analysis will be used on a set of bricks of the medieval manufacture to determine where they might have been manufactured.

\section{Archaeological context and samples}

The Burkhan Khaldun is one of the Khentii Mountains in the Khentii Province of northeastern Mongolia. The mountain and its surrounding sacred landscape are associated with Genghis Khan's birth place as described in 'The Secret History of the Mongols'. It was inscribed as a UNESCO World Heritage Site on 4 July 2015 under the title «Great Burkhan Khaldun Mountain and its surrounding sacred landscape.» The brick sample Bkh- 8 associated with the remains of the Buddhist temple 'Dund Ovooni sum' located at the Burkhan Khaldun Mountain formed basis for this study.

Table 1. Sample description

\begin{tabular}{|l|l|l|}
\hline Sample ID & \multicolumn{1}{|c|}{ Archaeological context } & \multicolumn{1}{|c|}{ Macroscopic features } \\
\hline Bkh-8 & $\begin{array}{l}\text { Buddhist temple 'Dund ovooni takhilyn sum' at Burkhan } \\
\text { Khaldun Mountain }\end{array}$ & Brick, blue grey colored, D=40 mm \\
\hline K02/06 & $\begin{array}{l}\text { Erdene-Zuu wall trench on the outside of the Northern } \\
\text { wall, 2005 }\end{array}$ & Brick, blue grey colored, D=45 mm \\
\hline EZ-1 & Erdene-Zuu main church building 'Gol Dugan', 2010 & Brick, grey, D=55 mm \\
\hline KhD-1 & Avargyn Balgas, Khentii province, Delgerkhaan, 2003 & Brick fragment, Blue grey colored \\
\hline KhD-2 & Avargyn Balgas, Khentii province, Delgerkhaan, 2003 & Brick fragment, Blue grey colored \\
\hline
\end{tabular}

The known historical facts about the temple chronology suggest that the spiritual temple was built at the beginning of $14^{\text {th }}$ century, which gave an opportunity to test the luminescence method. However, the possibility of re-using ceramic building materials cannot be ruled out; it means there is a risk that the bricks are not contemporary to the construction of the structure under study.

For the compositional analysis additional 
samples of the medieval manufacture were introdu-ced. Sample K02/06 was collected from Erdene Zuu temple wall trench on the outside of the Northern wall, in Karakorum (MDKE, Mongolian-German Karakorum Expedition, 2005). K02/06 was dated back to the early $13^{\text {th }}$ century suggesting that the walls under Erdene Zuu were constructed in early construction phase of Karakorum at $1235 \pm 40$ AD. Sample EZ-1 originates from the Buddhist temple Erdene-Zuu and its main church building "Gol Dugan". The brick fragments KhD-1, KhD-2 were collected from the excavations carried at medieval Avargyn Balgas, Khentii province in 2003. For the later samples no OSL data were available. Brick samples collected for mineralogical analysis, their archaeological context and main macroscopic features of the samples are summarized in Table 1.

\section{Experimental details}

All luminescence measurements were carried out at the luminescence laboratory at the MPI, Leipzig. The outer layer of sample was removed and the obtained core of the sampled brick fragments was carefully crushed in a hydraulic press and sieved. The coarse grains $(>100 \mu \mathrm{m})$ were then treated with hydrogen peroxide $\left(\mathrm{H}_{2} \mathrm{O}_{2}, 15 \%\right.$ and $\left.30 \%\right)$ to remove any organic material, followed by digestion in hydrochloric acid $(\mathrm{HCl}, 10 \%)$ to dissolve carbonates, prior to density separation using a heavy liquid (lithium heterotungstate) to obtain quartz and potassium feldspar rich fractions. No coarse grains of quartz (90$180 \mu \mathrm{m}$ ) were available; therefore $2 \mathrm{~mm}$ feldspar aliquots were prepared for luminescence measurements. Polymineral fine-grains (4$11 \mu \mathrm{m})$ were treated with hydrogen peroxide $(\mathrm{H} 2 \mathrm{O} 2,15 \%$ and 30\%), hydrochloric acid $(\mathrm{HCl}, 10 \%)$, dispersal using sodium oxalate, followed by isolation via Stokes settling [12]. Single aliquot discs were prepared for fine grain measurement using a pipette with the material suspended in a water-based solution.

All luminescence measurements were done using a Risø TL-DA-20 reader [13] equipped with ${ }^{90} \mathrm{Sr} /{ }^{90} \mathrm{Y}$ beta source. The infrared stimulated $\left(870 \pm 40 \mathrm{~nm}, 130 \mathrm{mWcm}^{-}\right.$ $\left.{ }^{2}\right)$ signal from feldspar was detected using D410 interference filter. Equivalent doses of feldspar and of polymineral fine grains were determined using the post-infrared infrared stimulated luminescence (pIRIR) [10] protocol. The luminescence signal was calculated as the integral from the initial $4 \mathrm{~s}$ minus the final $10 \mathrm{~s}$ of each $100 \mathrm{~s} \mathrm{IR}_{50}$, and from the initial 7.6s minus the final 20 s of the 100 s pIRIR $_{225}$ stimulation, respectively.

For the evaluation of alpha and beta contribution from the ceramic the external layers of the brick sample were used. The radionuclide concentrations of $\mathrm{K}, \mathrm{U}$ and $\mathrm{Th}$ measured in powdered sample using neutron activation analysis (NAA) were converted to dose rate data using the conversion factors from [14]. The internal dose rate was calculated for feldspar assuming a potassium content equal to $12.5 \pm 0.5 \%$ [15]. The beta dose rates determined on pulverized portion of brick directly by beta counting were compared with the calculated using NAA and the ratio was 1.19 .For polymineral fine-grains, ' $\alpha$-values' of $0.10 \pm 0.02$ and $0.12 \pm 0.02$ were used for $\mathrm{IR}_{50}$ and pIRIR measurements, respectively. The contribution from cosmic radiation to the dose rate was calculated following [16], assuming an uncertainty of $5 \%$. In-situ water content measured shortly after sampling $(0.22 \%)$ was taken into account.

RHX (rehydroxylation) measurements were carried out using the procedure described in [14], X-ray diffraction and infrared FT-IR measurements were carried out at the Institute of Physics and Technology. The mineral phase analysis was carried out on a Shimadzu Maxima XDR-700 diffractometer (CuK $\alpha$ radiation, $0.02^{\circ} 2 \Theta$ step size, $\left.5^{\circ}-80^{\circ}\right)$. X-ray fluorescence was carried out in Geological laboratory using a AXIOS - wave-lengthdispersive X-ray fluorescence spectrometer (PANalytical) with an $\mathrm{Rh}$ excitation source. 
Table 2. Concentration of radionuclides measured using the low-background gamma spectrometry, neutron activation analysis NAA and X-ray fluorescence analysis.

\begin{tabular}{|c|c|c|c|}
\hline Sample & $K(\%)$ & $U($ ppm $)$ & $T h($ ppm $)$ \\
\hline BKh-08 & $3.45 \pm 0.24^{a}$ & $2.48 \pm 0.13^{a}$ & $13.07 \pm 1.96^{a}$ \\
\hline BKh-08 & $2.80 \pm 0.168^{b}$ & $1.70 \pm 0.153^{b}$ & $8.34 \pm 0.25^{b}$ \\
\hline BKh-08 & $2.87^{c}$ & & $13^{c}$ \\
\hline
\end{tabular}

${ }^{a}$ Gamma spectrometry (Dresden)

${ }^{b}$ Neutron activation analysis NAA, (CEZA Mannheim).

${ }^{c} X$-ray fluorescence analysis XRF, (Geolab, Ulanbaatar)

\section{RESULTS AND DISCUSSION}

\section{XRD, XRF and RHX results}

The major minerals (Fig. 1) of the Burkhan Khaldun bricks are quartz, feldspar (microcline) and plagioclase (albite). However, KA6 contained muscovite, which is thermally stable up to $900^{\circ} \mathrm{C}$. The maximum thermal stability of plagioclase and potassium feldspar is at $1000-1050^{\circ} \mathrm{C}$, implying the firing temperature of Bkh- 8 was between 900 and $1000 \mathrm{oC}$. Set of data of ceramic samples from Karakorum and set from ceramic from Avargyn Balgas were introduced to figure out where the samples might have come from. Comparing the major and trace elements of the bricks, we can determine whether the bricks came from the same sources or raw materials. Similarities in mineral composition within the groups can be recognized between the brick Bkh- 8 and $\mathrm{K} 2 / 06$; later is grey colored brick collected from the wall trench on the outside of the Northern wall of Erdene Zuu.

The results obtained using the RHX dating approach on Bkh-8 yield a date $1270 \pm 60$ AD.
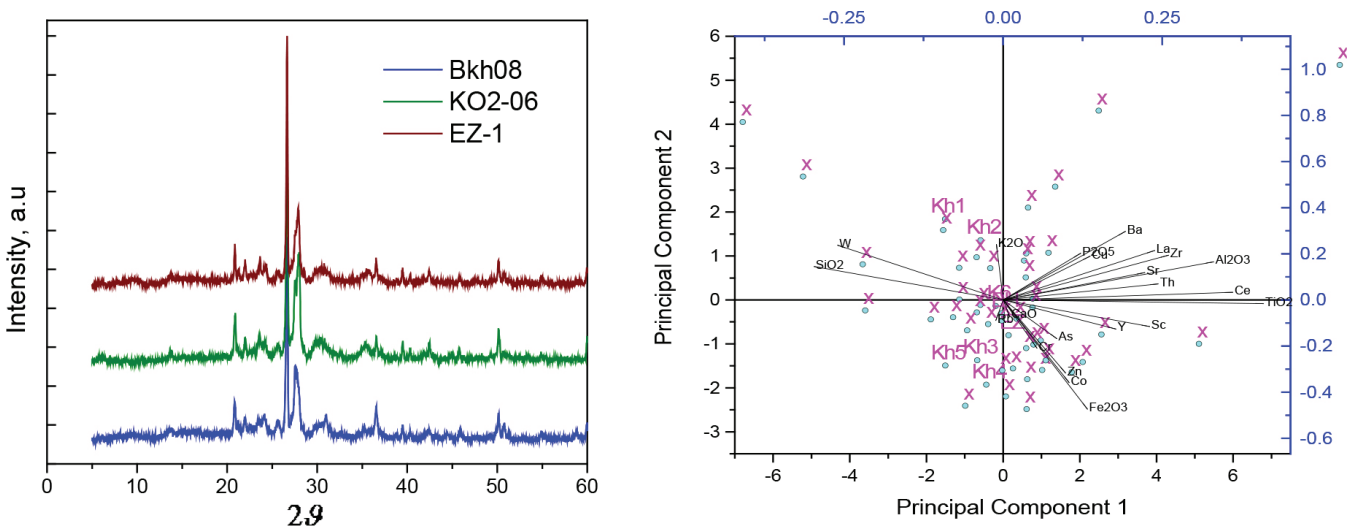

Figure 1. Left: The XRD patterns of the sample Bkh08 compared to the samples from collected Karakorum. Right: Principal component analyses

\section{Luminescence results}

In the following, the conventional IRSL $_{50}$ and the pIRIR protocols (Table 3 ) were tested on coarse grains as well as on polymineral fine grains from fired feldspar sample Bkh-8. 
Table 3. Protocols used in this work - conventional IRSL and pIRIR.

\begin{tabular}{lll}
\hline Step & Protocol: IRSL & Protocol: pIRIR210 \\
\hline 1 & Give dose , Di & Give dose , Di \\
2 & Preheat for $10 \mathrm{~s}$ at $210^{\circ} \mathrm{C}-290^{\circ} \mathrm{C}$ & Preheat for $10 \mathrm{~s}$ at $180^{\circ} \mathrm{C}-290^{\circ} \mathrm{C}$ \\
3 & Optical stimulation with IRSL for $100 \mathrm{~s}$ at $50^{\circ} \mathrm{C}$ & Optical stimulation with IR for $100 \mathrm{~s}$ at $50^{\circ} \mathrm{C}$ \\
& & Optical stimulation with IR for $100 \mathrm{~s}$ at $150^{\circ} \mathrm{C}-240^{\circ} \mathrm{C}$ \\
& & Test dose, $1 \mathrm{G} \mathrm{y}$ \\
5 & Test dose, $1 \mathrm{G} \mathrm{y}$ & Preheat for $10 \mathrm{~s}$ at $180^{\circ} \mathrm{C}-290^{\circ} \mathrm{C}$ \\
6 & Preheat for $10 \mathrm{~s}$ at $210^{\circ} \mathrm{C}-290^{\circ} \mathrm{C}$ & Optical stimulation with IR for $100 \mathrm{~s} \mathrm{at} 50^{\circ} \mathrm{C}$ \\
& & Optical stimulation with IR for $100 \mathrm{~s}$ at $150^{\circ} \mathrm{C}-240^{\circ} \mathrm{C}$ \\
7 & Return to step 1 & Return to step 1 \\
\hline
\end{tabular}

\subsection{IRSL $_{50}$ and PIRIR on coarse grains of feldspar}

The temperature dependence of $\mathrm{IRSL}_{50}$ was studied for a preheat temperature between $210^{\circ} \mathrm{C}$ and $290^{\circ} \mathrm{C}$ and the mean De values for IRSL50 signals are plotted against the preheat temperature in Fig.2. It should be noted that the measurements were carried out using $1 \mathrm{~mm}$ aliquots, which is nearly a single-grain technique. There is an overall De plateau between $225^{\circ} \mathrm{C}$ and $260^{\circ} \mathrm{C}$ with the mean De of $3.08 \pm 0.12 \mathrm{~Gy}$; however, the $\mathrm{IRSL}_{50}$ signals (Fig.2b) appear to decrease with the increasing preheat temperature. No fading measurements were done on this sample, but assuming $\mathrm{g}$ values $\sim 2 \%$ (g-values between 0 and $5 \%$ was observed for different samples from different regions of the world); a preliminary value of 3.48Gy can be expected for Bkh-8.
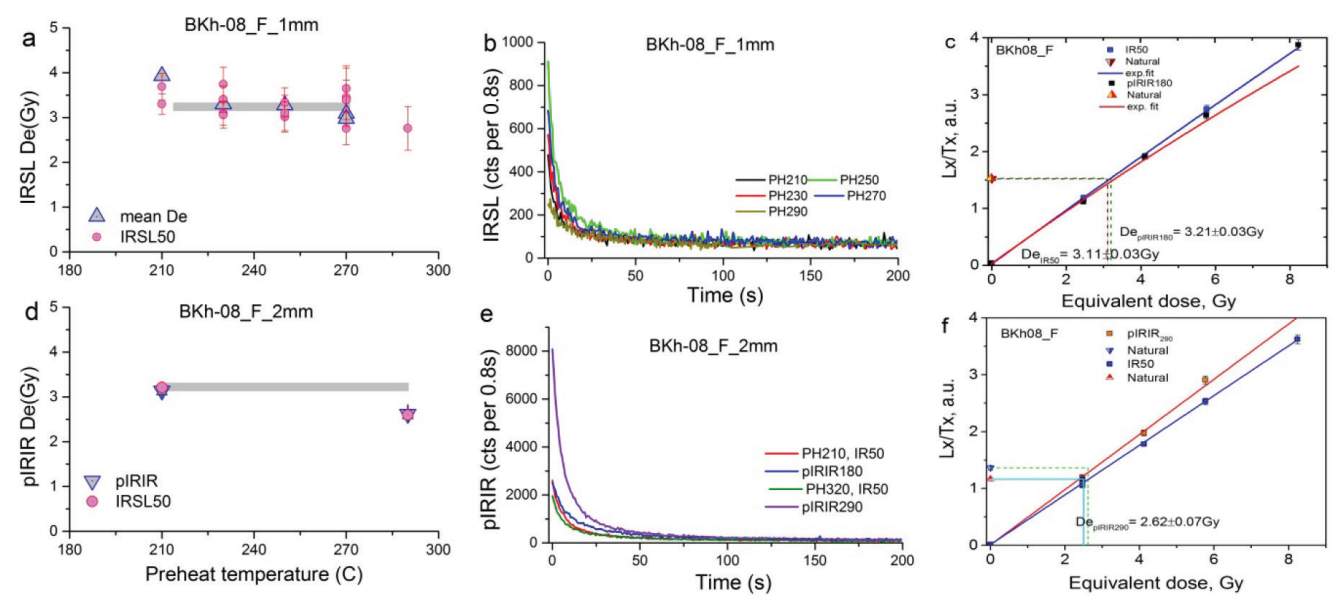

Figure 2. a) Effect of preheat temperature on IRSL De values for feldspar sample. Each data point represents the average of four $1 \mathrm{~mm}$ aliquots. The grey bar represents the De plateau; $b)$ IRSL decay curves; d) IR $R_{50}$ and pIRIR ${ }_{180^{\circ}}$ pIRIR ${ }_{290}$ De values for feldspar. e) $I R_{50}$ and pIRIR ${ }_{180^{\circ}}$ pIRIR ${ }_{290}$ decay curves; $c, f)$ The dose response curves $L x / T x=f(D e)$ constructed using pIRIR ${ }_{180}$ and pIRIR ${ }_{290}$ measurements for feldspar sample Bkh-8. De obtained using pIRIR ${ }_{180}$ and pIRIR $290^{\circ}$ 
Subsequently, a pIRIR protocol for young samples was employed using a preheat of $210^{\circ} \mathrm{C}$ and stimulation temperature of $180^{\circ} \mathrm{C}$; at low stimulation temperatures the residual dose is minimized [15]. Twelve $2 \mathrm{~mm}$ aliquots of coarse feldspar were measured using pIRIR $_{180}$ protocol and yielded $\mathrm{De}_{\text {IR } 50}=3.26 \pm 0.03 \mathrm{~Gy}$; $\mathrm{De}_{\text {pIRIR } 180}=3.14 \pm 0.03 \mathrm{~Gy}$ and over-dispersion $\mathrm{OD}=1.2 \%$. Another set of aliquots were measured using the high temperature pIRIR $_{290}$ protocol which yielded $\mathrm{De}_{290}$ of $2.62 \pm 0.07 \mathrm{~Gy}$; the corresponding dose response curves Lx/ $T x=f(D e)$ for both measurements are shown in Fig.2c,f. The decrease in pIRIR De towards higher preheat temperature was observed; this is similar to the previous $\mathrm{IRSL}_{50}$ measurements, however, this is in contrast to the increase in pIRIR De reported for unheated feldspar, e.g.[16], which is explained in terms of the hard-to-bleach signals [17]. The results based on pIRIR $_{290}$ are considered as erroneous due to the behavior of the pIRIR ${ }_{290}$ signals; signals stimulated at higher temperature become harder to bleach resulting in considerable residual doses; therefore the pIRIR signal at lower stimulation has been suggested for young samples [16].

On the other hand, the sensitivity of pIRIR signals in unheated samples was reported to decrease with the increase of the stimulation temperature [17]. We examined the pIRIR ${ }_{180}$ and pIRIR $_{290}$ test dose signal intensities shown in Fig.2e; when comparing the pIRIR $_{290}$ intensities with the corresponding $\operatorname{IR}_{50}$ intensities, the ratio increased from ( $\mathrm{pIRIR}_{180}$ / $\left.\mathrm{IR}_{50}\right)$ to $\left(\mathrm{pIRIR}_{290} / \mathrm{IR}_{50}\right)$ from $\sim 1.5$ to $\sim 5$. Our study shows that for the well-bleached fired sample Bkh- 8 , the pIRIR $_{290}$ sensitivity increased towards higher preheats which can lead to the decrease of De estimates. Further investigations are needed to understand this effect.

\section{2. pIRIR on polymineral fine grains}

In the following, the pIRIR approach is carried out on polymineral fine grains; it is assumed that pIRIR on polymineral stimulates predominantly feldspar fine grains only [18]. The dependence of De values on the first IR stimulation temperature was investigated for fine grains for temperatures between $180^{\circ} \mathrm{C}$ and $270^{\circ} \mathrm{C}$. Fig. $3 a, d$ show that both IR50 and pIRIR De values are decreasing towards higher stimulation temperatures. This is in agreement with the previous results obtained from IRSL and pIRIR measurements on coarse grains of feldspar. De obtained using pIRIR ${ }_{150}$ is $6.7 \pm 0.2 \mathrm{~Gy}$, whereas De obtained using pIRIR $_{240}$ yielded 3.87 $\pm 0.09 \mathrm{~Gy}$; nevertheless a preheat plateau is present between $240^{\circ} \mathrm{C}$ and $270^{\circ} \mathrm{C}$.
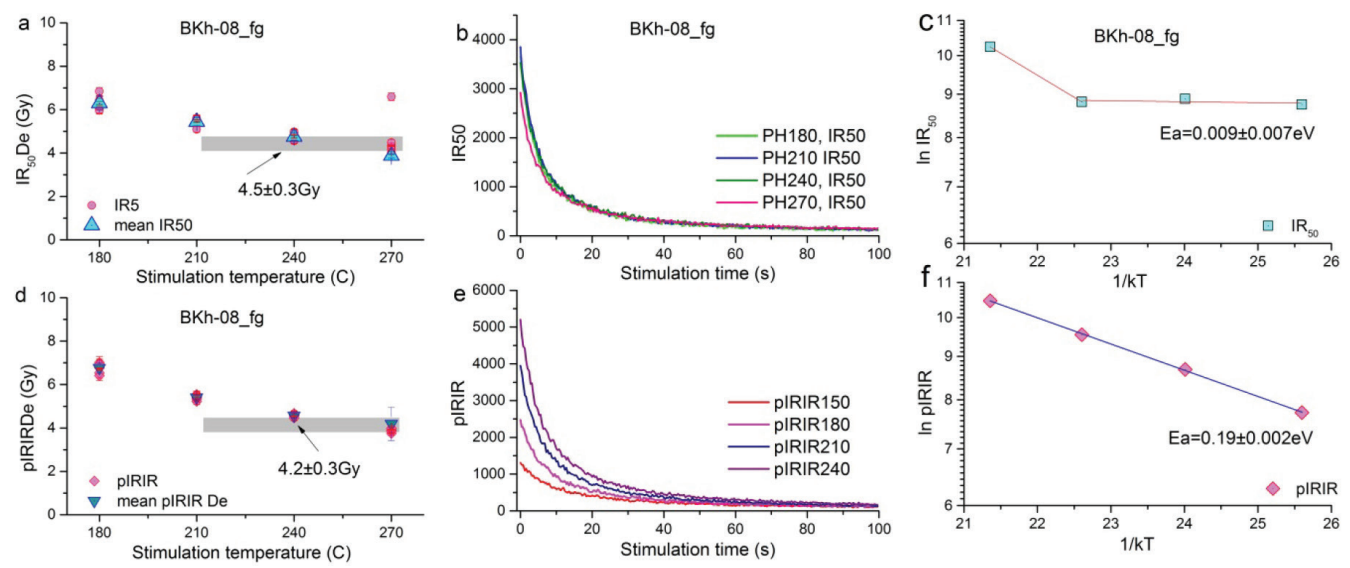

Figure 3. Dependence of De values on the first IR stimulation temperature for the polymineral fine grain sample Bkh-8 for a) $I R_{50}$ and d) pIRIR De. Each data point represents the mean of four aliquots. $b$ ) The $I R_{50}$ test dose signals and e) the pIRIR test dose signals; c) and f) Arrhenius plot of the $I R_{50}$ and pIRIR signals. 
The $\mathrm{IR}_{50}$ and pIRIR test dose signal intensities are shown in Fig.3b and Fig.3e; the pIRIR signals are increasing towards the higher preheat temperatures. For the $\mathrm{IR}_{50}$ there is almost no change in the intensity until the first IR stimulation temperature reached $240^{\circ} \mathrm{C}$. Examination of the $\mathrm{pIRIR} / \mathrm{IR}_{50}$ ratio intensities exhibited an increase from 0.5 to $\sim 2$ as the stimulation temperature increased, the pIRIR intensity was higher than the $\mathrm{IR}_{50}$ signal at $\sim 240^{\circ} \mathrm{C}$.

The $\mathrm{IR}_{50}$ and pIRIR test dose signal intensities are shown in Arrhenius plots in Fig.3c,f; the slope of the plot is interpreted as the activation energy for each signal. For the pIRIR signal the values of $0.19 \pm 0.002 \mathrm{eV}$ were obtained which were consistent with the value of $0.22 \pm 0.025 \mathrm{eV}$ reported in [19]. Interestingly, our measurements results shown in Fig. $3 \mathrm{f}$ for $\mathrm{IR}_{50}$ indicate that there is no change in the intensity of $\mathrm{IR}_{50}$ up to temperature $240^{\circ} \mathrm{C}$, but an abrupt change in the activation energy coincides with the existing preheat plateau between $240^{\circ} \mathrm{C}$ and $270^{\circ} \mathrm{C}$. The results imply that pIRIR ${ }_{240}$ measurements yielded the De values of $3.87 \pm 0.09$ Gy which are derived from the most stable traps.

\section{Luminescence ages}

The range of doses between $2.60 \pm 0.20$ Gy to $3.87 \pm 0.09$ Gy based on the $\operatorname{IRSL}_{50}$ and pIRIR signals from coarse and fine grains of feldspar were obtained in this study. From the IRSL $_{50}$ and pIRIR $_{180}$ measurements coarse feldspar doses of $3.08 \pm 0.20$ Gy and $3.14 \pm 0.03$ Gy were obtained, which are consistent with each other.

Dating polymineral fine grains, a higher preheat is more likely to give a stable pIRIR signal without any contribution of unstable traps. In our case, the signals in unstable traps were not emptied up to $240^{\circ} \mathrm{C}$ and contributed to the pIRIR signals. Therefore the De's obtained in the temperature range from $180^{\circ} \mathrm{C}$ and $240^{\circ} \mathrm{C}$ reflect the contribution of unstable traps; the doses range from $6.7 \pm 0.2 \mathrm{~Gy}$ to $4.2 \pm 0.3$ Gy. A high preheat temperature of $270^{\circ} \mathrm{C}$ generated a more stable pIRIR $_{240}$ signal yielding the values of $3.87 \pm 0.09 \mathrm{~Gy}$.

Table 4. Luminescence results.

\begin{tabular}{lccccc}
\hline $\begin{array}{l}\text { Sample } \\
\text { Mineral fraction }\end{array}$ & Method & $\begin{array}{c}\text { Dose rate Dr } \\
(\text { Gy } / \mathrm{ka})\end{array}$ & $\begin{array}{c}\text { CAM De } \\
(\mathrm{Gy})\end{array}$ & $\underline{\text { Age, years }}$ & Date, AD \\
\hline $4 \div 11 \mu \mathrm{m}$ & pIRIR $_{240}$ & $4.92 \pm 0.25$ & $3.87 \pm 0.09$ & $790 \pm 50$ & $1230 \pm 50$ \\
\hline \multirow{3}{*}{$100 \div 150 \mu \mathrm{m}$} & IRSL50 & $4.26 \pm 0.14$ & $3.08 \pm 0.20$ & $720 \pm 60$ & $1290 \pm 60$ \\
& pIRIR $_{180}$ & & $3.14 \pm 0.03$ & $740 \pm 40$ & $1280 \pm 40$ \\
\hline
\end{tabular}

The final luminescence ages are derived from the ration of the absorbed radiation dose De and the dose-rate Dr; the data are summarized in Table 4. Given that luminescence dating determines the last heating event, the dates of $1290 \pm 60 \mathrm{AD}$ and $1230 \pm 60 \mathrm{AD}$ can be considered as the date of manufacturing of bricks, but not necessarily the time of temple construction. Based on the archaeological interpretations, the site is believed to have been constructed during the end of the $13^{\text {th }}$ century; however, if the bricks had been reused or perhaps been relocated or reheated, a date of construction later than $1290 \pm 60 \mathrm{AD}$ is expected for the temple.

\section{CONCLUSIONS}

The coarse and polymineral fine grains of feldspar have been investigated using the conventional IRSL and pIRIR approach; all IRSL, IR $_{50}$ and pIRIR signals showed a decreasing tendency of the De plateau, in particular, the pIRIR signals do not deplete at 
higher preheats although the fired brick sample under study had been well bleached prior burial. The effect of residuals contained in the hard-tobleach pIRIR signals was not observed; indeed the effect of increasing sensitivity changes was detected. For the polymineral fine grains, a higher preheat is more likely to give a stable pIRIR signal without any contribution of the unstable traps below $270^{\circ} \mathrm{C}$.

The convergence of all luminescence ages (e.g. pIRIR ${ }_{180}$ on coarse feldspar of $1280 \pm 40$ $\mathrm{AD}, \mathrm{pIRIR}_{240}$ on fine grains of $1230 \pm 50 \mathrm{AD}$ ) was found; in addition, a similarity of the mineral composition of the brick under study with the bricks associated with the first construction phase at the Karakorum was observed. Consequently, the original place and date of the temple's manufacture in Burkhan Khaldun is Karakorum city at $1280 \pm 40$ AD. However, the possibility of re-using of building materials which falls into the time period of the extensive construction in Karakorum cannot be ruled out, and the temple construction at the later time period is expected.

\section{ACKNOWLEDGEMENTS}

The luminescence measurements were done at the Max Planck Institute for evolutionary anthropology (Leipzig, Germany); the support of Prof. J.-J.Hublin is acknowledged. The research was funded by a Research grant 14-

241 RG/PHYS/AS-G from TWAS (The World Academy of Sciences) to Saran Solongo. We thank the anonymous reviewer whose comments improved the paper significantly.

\section{REFERENCES}

1. Bailiff, I.K., Archaeometry 49, 2007: p. 827-851.

2. Murray, A.S. and A.G. Wintle, The single aliquot regenerative dose protocol: potential for improvements in reliability. Radiation Measurements, 2003. 37(4-5): p. 377-381.

3. Guibert, P., et al., When were the walls of the Chauvet-Pont d'Arc Cave heated? A chronological approach by thermoluminescence. Quaternary Geochronology, 2015. 29: p. 36-47.

4. Blain, S., et al., An intercomparison study of luminescence dating protocols and techniques applied to medieval brick samples from Normandy (France). Quaternary Geochronology, 2010. 5(2-3): p. 311-316.

5. С.Саран and T. Галбаатар, pre-prints of the Institute of Physics and technology \#31, 2003.

6. Hüttel, H.G. and U. Erdenebat, Karabalgasun and Karakorum. Two late nomadic urban settlements in the Orkhon Valley, Ulaanbaatar. 2011.

7. Solongo, S., G.A. Wagner, and T. Galbaatar, The estimation of using the fast and medium components in fired quartz from archaeological site Karakorum, Mongolia. Radiation Measurements, 2006. 41(7-8): p. 1001-1008.

8. Solongo, S., G.A. Wagner, and T. Galbaatar, On the origin of dose distributions in quartz extracted from archaaeological ceramics in Karakorum, Mongolia. Proceedings of the Mongolian Academy of Sciences, 2006. 181(3): p. 3-13.

9. Wintle, A.G., Anamalous fading of thermoluminescence in mineral samples. Nature, 1973. 245: p. 143-144.

10. Buylaert, J.P., et al., A robust feldspar luminescence dating method for Middle and Late Pleistocene sediments. Boreas, 2012. 41(3): p. 435-451.

11. Wilson, M.A., et al., Rehydroxylation (RHX) dating of archaeological pottery. Proceedings of the Royal Society of London A: Mathematical, Physical and Engineering Sciences, 2012. 468(2147): p. 3476-3493.

12. Solongo, S., et al., OSL and TL characteristics of fine grain quartz from Mongolian prehistoric pottery used for dating. Geochronometria, 2014. 41(1): p. 15-23. 
13. Bøtter-Jensen, L., et al., Developments in radiation, stimulation and observation facilities in luminescence measurements. Radiation Measurements, 2003. 37(4-5): p. 535-541.

14. С.Саран, С.Тэнгис, and Б.Оргил, Керамикийн регидроксилачийн туршилтын Үр дүн ФТХийн бүтээл 43 in print, 2017.

15. Reimann, T. and S. Tsukamoto, Dating the recent past ( $<500$ years) by post-IR IRSL feldspar - Examples from the North Sea and Baltic Sea coast. Quaternary Geochronology, 2012. 10: p. 180-187.

16. Solongo, S. and S. Tengis, The feldspar pIRIR and quartz OSL on silty-clay sediments from walled Ramparts in Orkhon valley, Mongolia. Quaternary Geochronology, 2015.

17. Chen, Y., S.H. Li, and B. Li, Residual doses and sensitivity change of post IR IRSL signals from potassium feldspar under different bleaching conditions. Geochronometria, 2013. 40(4): p. 229238.

18. Buylaert, J.-P., et al., A detailed post-IR IRSL chronology for the last interglacial soil at the Jingbian loess site (northern China). Quaternary Geochronology, 2015. 30, Part B: p. 194-199.

19. Tsukamoto, S., et al., A comparative study of the luminescence characteristics of polymineral fine grains and coarse-grained K-, and Na-rich feldspars. Radiation Measurements, 2012. 47. p. 903-908. 